\title{
The influence of mesoscale and submesoscale heterogeneity on ocean biogeochemical reactions
}

\author{
M. Levy ${ }^{1}$ and A. P. Martin ${ }^{2}$ \\ Received 1 October 2012; revised 1 October 2013; accepted 8 October 2013; published 20 November 2013.
}

[1] The oceanic circulation in the meso to submesoscale regime generates heterogeneity in the concentrations of biogeochemical components over these scales, horizontally between 1 and $100 \mathrm{~km}$. Due to nonlinearities in the biogeochemical reactions, such as phytoplankton primary production and zooplankton grazing, this small-scale heterogeneity can lead to departure from the mean field approximation, whereby plankton reactions are evaluated from mean distributions at coarser scale. Here we explore the magnitude of these eddy reactions and compare their strength to those of the more widely studied eddy transports. We use the term eddy to denote effects arising from scales smaller than $\sim 100 \mathrm{~km}$. This is done using a submesoscale permitting biogeochemical model, representative of the seasonally varying subtropical and subpolar gyres. We found that the eddy reactions associated with primary production and grazing account for $\pm 5-30 \%$ of productivity and grazing, respectively, depending on location and time of year, and are scale dependent: two thirds are due to heterogeneities at scales $30-100 \mathrm{~km}$ and one third to those at scales below $30 \mathrm{~km}$. Moreover, eddy productivities are systematically negative, implying that production tends to be reduced by nonlinear interactions at the mesoscale and smaller. The opposite result is found for eddy grazing, which is generally positive. The contrasting effects result from vertical advection, which negatively correlates phytoplankton and nutrients and positively correlates phytoplankton and zooplankton in the meso to submesoscale range. Moreover, our results highlight the central role played by eddy reactions for ecological aspects and the distribution of organisms and by eddy transport for biogeochemical aspects and nutrient budgets.

Citation: Levy, M., and A. P. Martin (2013), The influence of mesoscale and submesoscale heterogeneity on ocean biogeochemical reactions, Global Biogeochem. Cycles, 27, 1139-1150, doi:10.1002/2012GB004518.

\section{Introduction}

[2] Biogeochemical species such as phytoplankton, zooplankton, and nutrients invariably display patchiness at the mesoscale and submesoscale [e.g., Tsuda et al., 1993; Martin and Srokosz, 2002; Martin, 2003; Lehahn et al., 2007; d'Ovidio et al., 2010; Johnson et al., 2010]. This patchiness results from stirring of large-scale gradients by the turbulent oceanic flow [Abraham, 1998; Lévy and Klein, 2004], by direct forcing through localized upwelling [Martin et al., 2002; Pasquero et al., 2005] and through biogeochemical reactions triggered by such perturbations [Srokosz et al., 2003]. It can affect ocean productivity because of

Additional supporting information may be found in the online version of this article.

${ }^{1}$ LOCEAN-IPSL, CNRS/IRD/UPMC/MNHN, Paris, France.

${ }^{2}$ NOC, Southampton, UK.

Corresponding author: M. Levy, LOCEAN-IPSL, CNRS/IRD/UPMC/ MNHN, 4 Place Jussieu, FR-75252 Paris Cedex 05, France. (marina@locean-ipsl.upmc.fr)

(C)2013. American Geophysical Union. All Rights Reserved. 0886-6236/13/10.1002/2012GB004518 the nonlinearities in the primary production rates [Michaelis and Menten, 1913]. The effects arising from the spatial variability at these scales, denoted $e d d y$ effects here, are misrepresented in biogeochemical ocean general circulation models (BOGCMs) when they are too coarse to resolve eddy stirring. Yet coarse-resolution BOGCMs are commonly used to describe the ocean's carbon cycle and its variability. Primary production controls the intensity of the biological carbon pump, and its precise estimate is crucial. Here we examine whether taking into account small-scale heterogeneity in the distribution of biogeochemical species has an impact on the estimates of regional primary production and other key biogeochemical reactions, in such models.

[3] It is important to be clear at the outset about terminology. In the next section, we demonstrate how the eddy-mean decomposition leads to the appearance of what we refer to in the following as eddy reactions, in analogy with the eddy transports that appear from the filtering of turbulent fluctuations in momentum and tracer over the conservation equation for a tracer (see for instance Eden et al. [2007]). The filter determines what is meant by eddy and what is left in the mean. In this study, the term eddy will be used to indicate variability at the mesoscale and submesoscale $(\sim 1-100 \mathrm{~km})$. Each nonlinear biogeochemical reaction (such 
as primary production, grazing, mortality) is associated with an eddy reaction term (eddy productivity, eddy grazing, eddy mortality). Note also that to avoid confusion between biogeochemical fluxes and advective fluxes, we use the terminology biogeochemical reactions for biogeochemical fluxes and transport for advective fluxes; hence, what is often referred to as eddy fluxes in the literature (for advective eddy fluxes) are what we call eddy transport.

[4] Several investigations have examined the contribution of nitrate eddy transport to the total nitrate supply fueling primary production [Oschlies, 2002; McGillicuddy et al., 2003; Lévy et al., 2012a]. These eddy transports result from secondary ageostrophic circulations which can be large at the mesoscale and submesoscale [Klein et al., 2008; Thomas et al., 2008; Capet et al., 2008]. Although the matter of some debate [Oschlies, 2002; McGillicuddy et al., 2003], these studies suggest that eddy transports generally make a small contribution compared with winter convection and mean advection but present large regional contrasts and can locally dominate at the margins of subtropical gyres or in regions where other nutrients may be limiting [Allen et al., 2005].

[5] Eddy reactions have received much less attention than eddy transports. Despite several studies into eddy productivity in idealized diffusive or advective flows [Brentnall et al., 2003; Richards and Brentnall, 2006; Wallhead et al., 2008; Goodman and Robinson, 2008; Goodman, 2011], the relevance of eddy reactions under realistic oceanic conditions is still unknown. In fact, the role of the mesoscale and submesoscale heterogeneity in influencing global oceanic biogeochemistry is completely uncertain. Interestingly, an analogous problem concerns the chemical reactions in the stratosphere. Edouard et al. [1996] have shown that ozone depletion in the Arctic is sensitive to filament-scale inhomogeneities in the distribution of reactant species because of the nonlinearities in the chemical rate laws. Their modeling study suggests that the effect contributes $\sim 40 \%$ to the total. An effect of similar magnitude on primary production or grazing in the ocean would significantly call into question the mean field approximation of coarseresolution BOGCM.

[6] In this context, our goal is to evaluate the contribution of eddy reactions to basin scale budgets under realistic oceanographic conditions. The importance of this contribution is evaluated in comparison with mean reactions and with eddy transports. The relative importance of eddy transports and eddy reactions is evaluated for nutrients, for phytoplankton, and for zooplankton, through the examination of three specific reactions: eddy productivity, eddy grazing, and eddy mortality.

[7] This is done in the framework of biogeochemical regimes characteristic of the North Atlantic or North Pacific subpolar and subtropical gyres, with a simple plankton model embedded in a submesoscale permitting ocean circulation model. Section 2 introduces some basic ingredients of the eddy-mean decomposition and the derivation of eddy fluxes and eddy reactions from this decomposition. Section 3 describes the model used for this study. The model evaluation of all terms that enter the nutrient, phytoplankton, and zooplankton equations, including the mean and eddy contributions, are presented in section 4 with the results discussed in section 5 .

\section{Eddy-Mean Decomposition of Biogeochemical Tracers Equations}

[8] In biogeochemical models, biogeochemical tracers, such as nutrients $N$, phytoplankton $P$, and zooplankton $Z$, obey the advection/diffusion equation to which an additional term is added to account for biogeochemical reactions. In the case of nutrients $N$, this can be written:

$$
\frac{\partial}{\partial t} N=-\underbrace{\nabla \cdot(N \boldsymbol{v})}_{A_{N}}+\underbrace{\partial_{z}\left(k_{z} \partial_{z} N\right)}_{D_{N}}+B_{N}
$$

[9] Advection $\left(A_{N}\right)$ is written here in a flux form assuming that the ocean is incompressible such that the 3-D flow $\boldsymbol{v}$ is non-divergent. Vertical turbulent diffusion $\left(D_{N}\right.$, with $k_{z}$ the vertical mixing coefficient) represents the three-dimensional, non-hydrostatic motions associated with mixing such as that due to breaking internal waves and convection. For simplicity, lateral diffusion, which is weak in the case of eddy-resolving ocean models, has been omitted from this equation. Biogeochemical reactions $B_{N}$ are described by functions, derived from laboratory experiments or theory, of the biogeochemical variables and sometimes of other environmental influences such as light or temperature. Importantly for the matter of this study, these functions are often nonlinear [e.g., Michaelis and Menten, 1913].

[10] The eddy-mean decomposition involves averaging equation (1), in order to separate the impact of the larger scales from the impact of the smaller scales. It implies the choice of a filter $\bar{N}=\frac{1}{\mathcal{S}} \int_{S} N \mathrm{~d} s$, where $\mathcal{S}$ is an element of surface area and/or time. With this filter, any variable $N$ can then be decomposed into a mean component $\bar{N}$ which comprises the variability above the cutoff scale $\mathcal{S}$ (large scale) and an eddy component $N^{\prime}$ which by definition satisfies $\overline{N^{\prime}}=0$ and comprises the variability below the cutoff scale (small scale): $N=\bar{N}+N^{\prime}$. Substituting for $N$ with $\bar{N}+N^{\prime}$ and $\boldsymbol{v}$ with $\overline{\boldsymbol{v}}+\boldsymbol{v}^{\prime}$ in equation (1) and then filtering leads to:

$$
\begin{aligned}
\frac{\partial}{\partial t} \bar{N}= & \underbrace{A_{\bar{N}}}_{\text {Mean Transport }}+\underbrace{A_{N}^{\prime}}_{\text {Eddy Transport }} \\
& +\underbrace{B_{\bar{N}}}_{\text {Mean Reaction }}+\underbrace{B_{N}^{\prime}}_{\text {Eddy Reaction }}+\underbrace{\overline{D_{N}}}_{\text {Vert Mixing }}
\end{aligned}
$$

[11] with the following notations:

[12] $A_{\bar{N}}=A_{N}(\bar{N}, \overline{\boldsymbol{v}})=-\nabla \cdot(\bar{N} \overline{\boldsymbol{v}})$

[13] $B_{\bar{N}}=B_{N}(\bar{N}, \bar{P}, \bar{Z}, \ldots)$

[14] $A_{N}^{\prime}=\overline{A_{N}}-A_{\bar{N}}=-\nabla \cdot\left(\overline{N^{\prime} v^{\prime}}\right)$

[15] $B_{N}^{\prime}=\overline{B_{N}}-B_{\bar{N}}$

[16] In equation (2), $A_{\bar{N}}$ represents the contribution of the large-scale advection to the evolution of $\bar{N} . B_{\bar{N}}$ represents the contribution of the biogeochemical reactions in the mean field approximation, i.e., assuming that biogeochemical tracers are homogeneously distributed below the cutoff scale. The contributions of the small scales appear in the eddy transports $A_{N}^{\prime}$ and eddy reactions $B_{N}^{\prime}$. Eddy transports $A_{N}^{\prime}$ only depend on small-scale quantities $\left(\mathrm{N}^{\prime}, \boldsymbol{v}^{\prime}\right)$. This ensues from the particular form of the advective flux which is bilinear in $\mathrm{N}$ and $\boldsymbol{v}$. However, eddy reactions $B_{N}^{\prime}$ depend on total fields $(\mathrm{N}, \mathrm{P}, \mathrm{Z}, \ldots$ ) because biogeochemical reactions often have nonlinear formulations [Donaghay and Osborn, 1997]. 


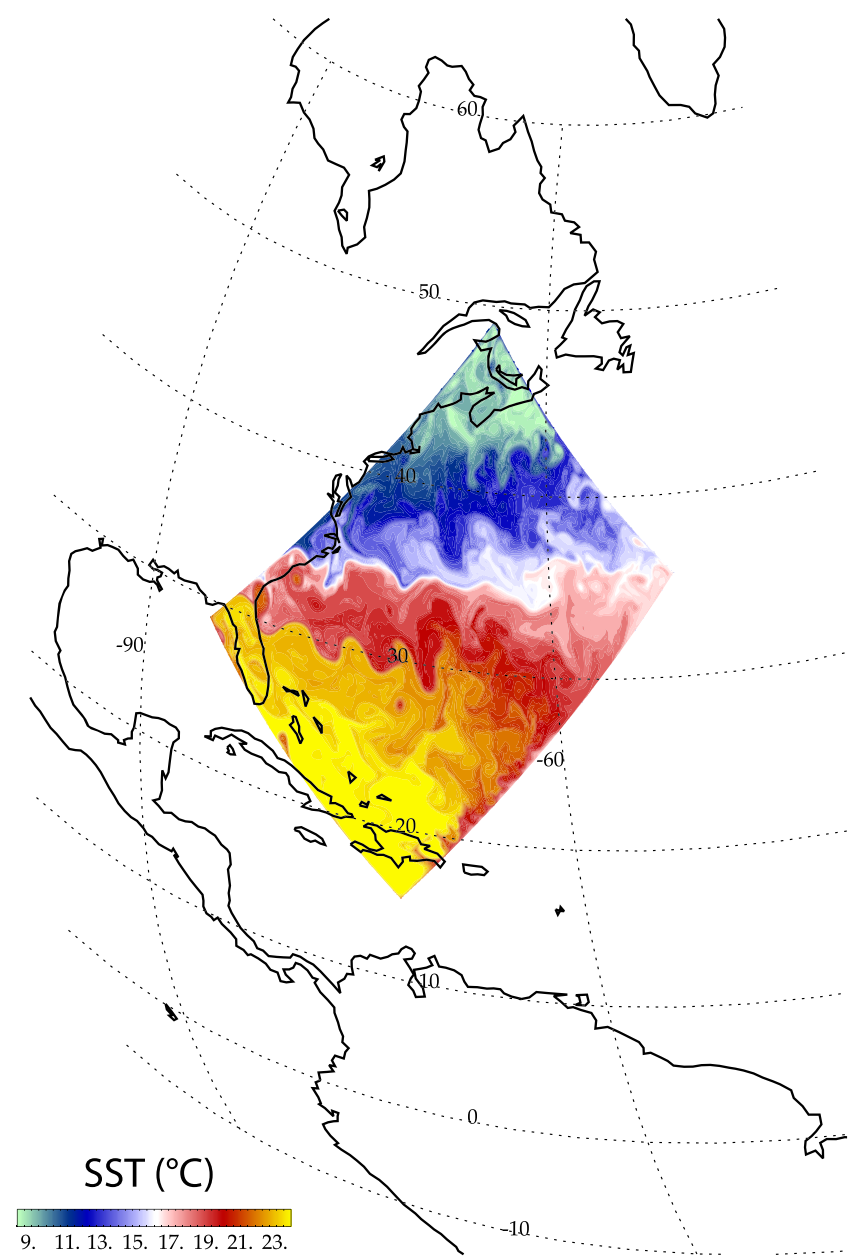

Figure 1. The rotated, rectangular, idealized model domain is representative of the western sector of the North Atlantic and characterized by a north-south gradient in sea surface temperature.

[17] The eddy reactions $B_{N}^{\prime}$ thus represent the largescale effects of the inhomogeneous distribution of the biogeochemical tracers below the cutoff scale. Coarseresolution BOGCM generally assume that $B_{N}$ only depends on mean fields, i.e., that $B_{N}^{\prime}=0$. In the following, we show that this assumption is not always valid.

\section{Methods}

\subsection{The High-Resolution Biophysical Model Experiment}

[18] The setting is a double gyre, meant to represent an idealized western sector of the North Atlantic or North Pacific Ocean (Figure 1). The domain is rectangular, of dimension $3180 \times 2120 \times 4 \mathrm{~km}$, rotated on the $\beta$-plane, and forced by seasonal zonal wind, heat and salt fluxes. The level coordinate free-surface primitive equation ocean model Nucleus for European Modeling of the Ocean [Madec, 2008] is used. The model grid has a horizontal resolution of $1 / 54^{\circ}$, which allows the simulation of an energetic mesoscale turbulence. Bi-harmonic friction and bi-harmonic diffusion along horizontal surfaces are used with the same value of $-10^{9} \mathrm{~m}^{4} \mathrm{~s}^{-1}$. Vertical mixing is parameterized by a turbulent closure model [Blanke and Delecluse, 1993], with a background value of $10^{-5} \mathrm{~m}^{2} \mathrm{~s}^{-1}$. Advection of temperature, salinity, and biogeochemical tracers is performed with a flux-corrected transport scheme [Lévy et al., 2001].

[19] The LOCEAN Ocean Biogeochemical System for Ecosystem and Resources (LOBSTER) biogeochemical model is embedded within the circulation model. It solves the evolution of six biogeochemical tracers: phytoplankton $(P)$, zooplankton $(Z)$, detritus $(D)$, dissolved organic matter $(\mathrm{DOM})$, nitrate $(\mathrm{N})$, and ammonium $(\mathrm{A})$, but in this work we focus on $\mathrm{N}, \mathrm{P}$, and $\mathrm{Z}$. The model solves for the uptake of nitrate by phytoplankton, the uptake of ammonium by phytoplankton, grazing of phytoplankton by zooplankton, and a simplified remineralization network, which involves excretion by zooplankton, dissolution of detritus, accumulation of semilabile DOM, remineralization of DOM into ammonium, and ultimately, nitrification of ammonium into nitrate. In the following and for simplicity, we will use the terminology "new production" (respectively "regenerated production") as synonym for "phytoplankton production based on nitrate" (respectively "on ammonium"), even though the use of nitrate and ammonium uptakes to measure new and regenerated production has been questioned. The biogeochemical model is fully tracer conserving with the same set of equations applied throughout the entire water column. The mathematical expressions of biogeochemical reactions in the model are described in Table 1 , with parameter values in Table 2. More detailed information

Table 1. LOBSTER Model Equations for Nitrate (N), Phytoplankton (P), and Zooplankton (Z)

\begin{tabular}{lc}
\hline Description & Equation \\
\hline Nitrate source/sink & $B_{N}=-\mathcal{P}_{n}+\mu_{n} A$ \\
Phytoplankton source/sink & $B_{P}=(1-\gamma) \mathcal{P}_{n}+(1-\gamma) \mathcal{P}_{a}-\mathcal{G}_{p}-m_{p} P$ \\
Zooplankton source/sink & $B_{Z}=a_{z} \mathcal{G}_{p}+a_{z} \mathcal{G}_{d}-\mathcal{M}_{z}-\mu_{z} Z$ \\
\hline Phytoplankton production on nitrate & $\mathcal{P}_{n}=\mathcal{P}_{n}(P, N, A, I)=\mu_{p} \frac{I}{I+K_{l}} \frac{N}{N+K_{n o 3}} e^{-\psi A} P$ \\
Phytoplankton production on ammonium & $\mathcal{P}_{a}=\mathcal{P}_{a}(P, A, I)=\mu_{p} \frac{I}{I+K_{l}} \frac{A}{A+K_{n h_{4}}} P$ \\
Grazing of phytoplankton & $\mathcal{G}_{p}=\mathcal{G}_{p}(P, Z, D)=g_{z} \frac{p P}{K_{z}+p P+(1-p) D} Z$ \\
Grazing of detritus & $\mathcal{G}_{d}=\mathcal{G}_{d}(P, Z, D)=g_{z} \frac{(1-p) D}{K_{z}+p P+(1-p) D} Z$ \\
Zooplankton quadratic loss & $\mathcal{M}_{z}=\mathcal{M}_{z}((Z))=m_{z} Z^{2}$ \\
\hline
\end{tabular}

${ }^{a}$ The same set of equation is applied over the entire water column. A model for light absorption [Lévy et al., 2005] is used to compute the photosynthetic available radiation (I) at each depth, as a function of the phytoplankton vertical profile and of the incoming solar radiation (SW). Thus, I varies with SW, with depth and with P. 
Table 2. LOBSTER Model Parameters Associated With the N, P, and Z Equations

\begin{tabular}{lccc}
\hline Parameter Name & Symbol & Value & Unit \\
\hline Nitrate limitation half saturation value & $K_{n o_{3}}$ & 0.7 & $\mathrm{mmol} \mathrm{m}^{-3}$ \\
Ammonium limitation half saturation value & $K_{n h 4}$ & 0.001 & $\mathrm{mmol} \mathrm{m}^{-3}$ \\
Inhibition of nitrate uptake by ammonium & $\psi$ & 3 & \\
Light limitation half saturation value & $K_{p a r}$ & 33. & $\mathrm{~W} \mathrm{~m}^{-2}$ \\
Phytoplankton maximal growth rate & $\mu_{p}$ & 1. & $\mathrm{day}^{-1}$ \\
Phytoplankton exudation rate & $\gamma$ & 0.05 & \\
Phytoplankton mortality rate & $m_{p}$ & 0.05 & $\mathrm{day}^{-1}$ \\
Grazing half saturation value & $K_{z}$ & 1 & $\mathrm{mmol} \mathrm{m}^{-3}$ \\
Zooplankton maximal grazing rate & $g_{z}$ & 0.8 & day $^{-1}$ \\
Assimilated food fraction by zooplankton & $a_{z}$ & 0.7 & day $^{-1}$ \\
Zooplankton excretion rate & $\mu_{z}$ & 0.07 & $\mathrm{~d}^{-1} \mathrm{mmol}^{-1} \mathrm{~m}^{3}$ \\
Zooplankton mortality rate & $m_{z}$ & 0.12 & \\
Zooplankton food preference & $p$ & 0.8 & $\mathrm{day}^{-1}$ \\
Nitrification rate & $\mu_{n}$ & 0.05 & \\
\hline
\end{tabular}

about the model configuration can be found in Lévy et al. [2010, 2012b].

[20] The model is spun-up at low resolution for 850 years from initial profiles constructed from the World Ocean Atlas climatologies by averaging over $25^{\circ} \mathrm{N}-30^{\circ} \mathrm{N}$ and $80^{\circ} \mathrm{W}-$ $0^{\circ} \mathrm{W}$ and then for 50 more years at full resolution. This allows the model to reach a repeating seasonal cycle, which is equilibrated in the upper $500 \mathrm{~m}$. The model equilibration implies the following:

$$
\begin{aligned}
\underbrace{\left\langle A_{\bar{N}}\right\rangle}_{\text {Mean Transport }} & +\underbrace{\left\langle A_{N}^{\prime}\right\rangle}_{\text {Eddy Transport }}+\underbrace{\left\langle\overline{D_{N}}\right\rangle}_{\text {Vert Diff }} \\
& +\underbrace{\left\langle B_{\bar{N}}\right\rangle}_{\text {Mean Reaction }}+\underbrace{\left\langle B_{N}^{\prime}\right\rangle}_{\text {Eddy Reaction }}=0
\end{aligned}
$$

where angle brackets denote the average over the 5 years of model data and over the top $120 \mathrm{~m}$. Model output is saved at 2 day frequency ( 2 day averages) for the last 5 years of the model integration. The filter used to separate the large-scale variations $\bar{N}$ (i.e., those associated with regional variations and with seasonality) from the eddy variations $N^{\prime}$ (i.e., those associated with the mesoscale and submesoscale) consists of a combined $2^{\circ}$ running average and 2 day climatology over the 5 years of model data. This filter cannot be applied within a $2^{\circ}$ band around the boundaries of our model which was therefore excluded from the analysis. The reader is referred to the supporting information for the description and justification of the methodology used to compute eddy transports and eddy reactions.

\subsection{Basic Features of the Model Solution}

[21] Some basic features of the model solution, already presented in Lévy et al. [2010] for the circulation and in Lévy et al. [2012b] for the biogeochemistry, are described here. The surface circulation is characterized by a strong meandering jet at approximately $30^{\circ} \mathrm{N}$, representative of the Gulf Stream or Kuroshio, which separates a northern subpolar gyre from a southern subtropical gyre (Figures $2 \mathrm{a}-2 \mathrm{~d}$ ). The jet is baroclinically unstable, and this instability is the main source of eddy energy in the model. Eddies are generated at the jet and strongly interact, leading to a complex mesoscale turbulence. The mesoscale turbulence is characterized by submesoscale fronts, of 0 (10) $\mathrm{km}$ width, associated with strong horizontal and vertical currents (Figures $2 \mathrm{a}$ and $2 \mathrm{~b}$ ). Some submesoscale fronts are organized into secondary zonal jets (such as the one close to $35^{\circ} \mathrm{N}$ in Figure 2a). There is a surface mixed layer whose depth varies regionally and seasonally; the deepest convection is obtained in winter in the northern subpolar gyre (Figure 2c); moderate convection occurs preferentially along a midlatitude band which starts south of the main jet at $27^{\circ} \mathrm{N}$ on the western side and extends to $35^{\circ} \mathrm{N}$ on the eastern side.

[22] The nitrate distribution is characterized by a raised nutricline in the subpolar gyre and depressed nutricline in the subtropical gyre, in agreement with the general distribution in the subpolar and subtropical gyres of the North Atlantic or North Pacific (Figure 3a). This, combined with a seasonally varying convection, leads to a strong seasonal supply of nitrate to the euphotic layer in the subpolar part of the domain, which feeds a strong phytoplankton bloom. In contrast, the nutrient supplies are smaller in the subtropical gyre, which is more oligotrophic. This leads to strong north-south gradient in the annual mean concentration of phytoplankton (Figure 3d) and zooplankton (not shown). Moreover, mesoscale turbulence leads to strong heterogeneity of the biogeochemical concentrations at small spatial scales, as illustrated by the snapshots of sea surface nitrate, phytoplankton and zooplankton (Figures 3a-3c). It is this heterogeneity which leads to eddy reactions. In the following, we examine the magnitude of this effect.

\section{Results}

\subsection{Evaluation of Eddy Reactions}

[23] We quantify the strength of eddy reactions in our model with a focus on the reactions that affect nitrate, phytoplankton, and zooplankton: new production $\left(\mathcal{P}_{n}\right)$, regenerated production $\left(\mathcal{P}_{a}\right)$, grazing of phytoplankton $\left(\mathcal{G}_{p}\right)$, grazing of detritus $\left(\mathcal{G}_{d}\right)$, zooplankton mortality $\left(\mathcal{M}_{z}\right)$, phytoplankton mortality $\left(m_{p} P\right)$, zooplankton excretion $\left(\mu_{z} Z\right)$, and nitrification $\left(\mu_{n} A\right)$ (Table 1). The last three reactions have a linear formulation, and thus, their associated eddy reactions are zero. Hence, we restrict the analysis to eddy productivity (new and regenerated), eddy grazing (on phytoplankton and on detritus), and eddy mortality of zooplankton.

\subsubsection{Seasonal Evolution}

[24] The seasonal evolution of mean and eddy biogeochemical reactions is examined separately in the model subpolar and subtropical gyres (Figure 4). These are empirically delimited by the $0.15 \mathrm{mmol} \mathrm{N} / \mathrm{m}^{3}$ annual mean surface phytoplankton contour (Figure 3). 
a) Horizontal velocity

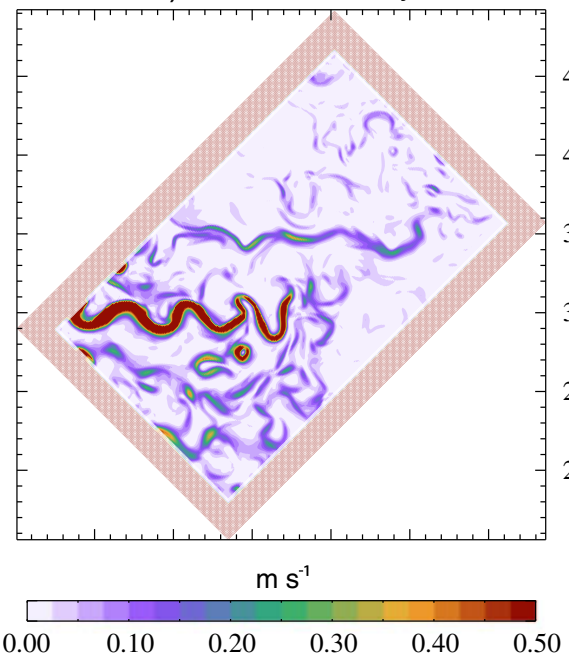

b) Vertical velocity

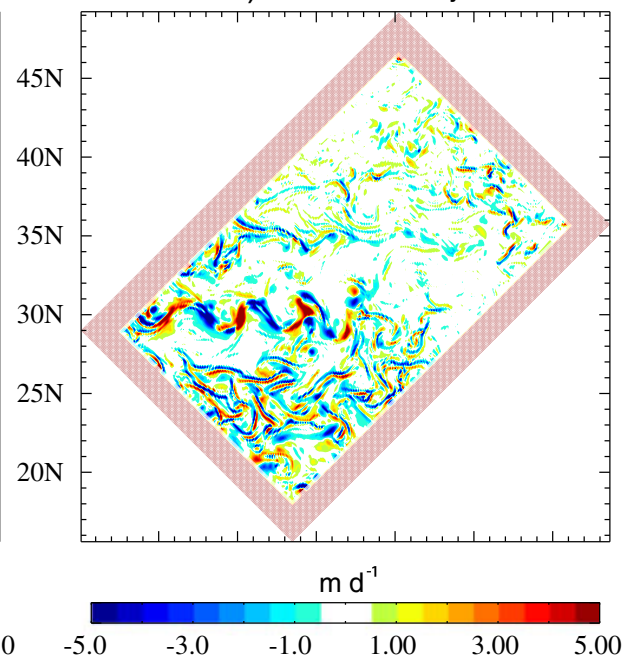

c) Mixed-layer depth

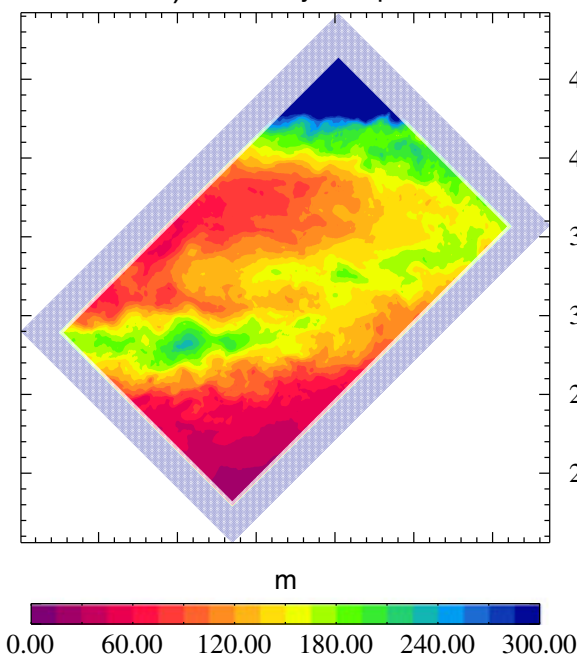

d) SST

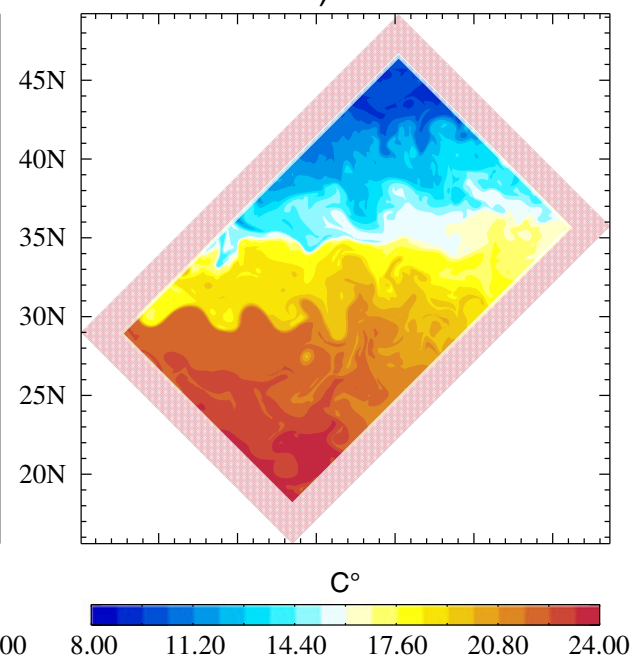

Figure 2. Model snapshots on 1 January of (a) modulus of horizontal velocity at the surface, (b) vertical velocity at $50 \mathrm{~m}$, and (d) sea surface temperature. (c) The climatological mixed-layer depth in winter in the model.

[25] In the subpolar gyre, all reactions display strong seasonal variations (plain lines, Figure 4a). Noticeably, there is a spring bloom which manifests itself through an increase in new production in spring, shortly followed by an increase in grazing. We can note that new production exceeds regenerated production. Grazing by zooplankton is an important phytoplankton loss term (stronger than phytoplankton mortality, not shown) and induces a strong coupling between phytoplankton and zooplankton. In the subtropical gyre (Figure $4 \mathrm{~b}$ ), the seasonal contrasts are less marked. The bloom occurs earlier in the season and has an amplitude which is about 5 times less than in the subpolar gyre. Regenerated production exceeds new production, and phytoplankton and zooplankton are not as strongly coupled. Thus, our model reproduces the typical characteristics of the seasonal evolution in the North Atlantic and North Pacific subpolar and subtropical regions.

[26] The seasonal evolution of the mean reactions (i.e., the reactions calculated from the mean field approximation, indicated by dashed lines in Figures $4 \mathrm{a}$ and $4 \mathrm{~b}$ ) follows very closely to that of the total reactions (plain lines) and is also generally very close in magnitude. This implies that eddy reactions are generally significantly smaller than mean reactions.

[27] Eddy production is always negative, and its contribution to production varies through the year between $-5 \%$ and $-40 \%$, both for new and regenerated production (Figures $4 \mathrm{c}$ and $4 \mathrm{~d})$. The strongest contributions $(\sim 40 \%)$ involve regenerated production during the bloom in the subpolar gyre and new production in summer in the subtropical gyre. Eddy grazing displays less seasonal variations. The contribution of eddy grazing is generally positive and varies between 5\% and $20 \%$, depending on the regime (subpolar versus subtropical) and on the type of grazing (on phytoplankton versus on detritus). Eddy mortality is close to zero in the subtropical gyre and less than $5 \%$ in the subpolar gyre.

\subsubsection{Zonal Variations}

[28] To complement the seasonal view, we examine the strong north-south contrast in our system. Figure 5 shows annual reactions averaged along the zonal direction and 
a) Nitrate

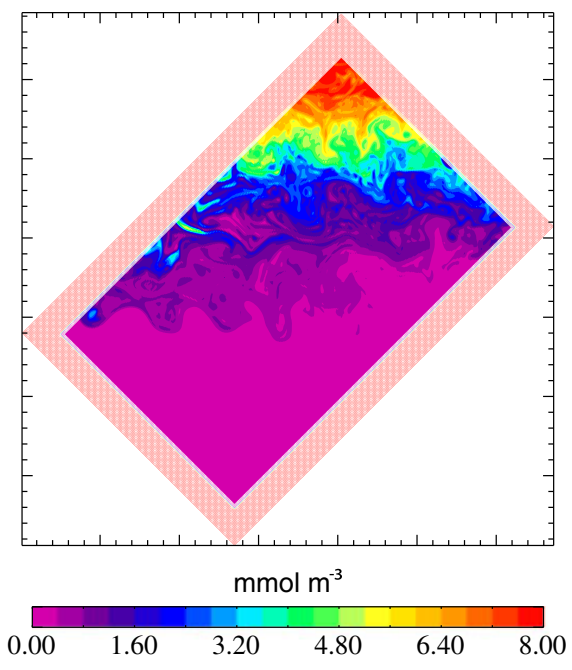

c) Zooplankton

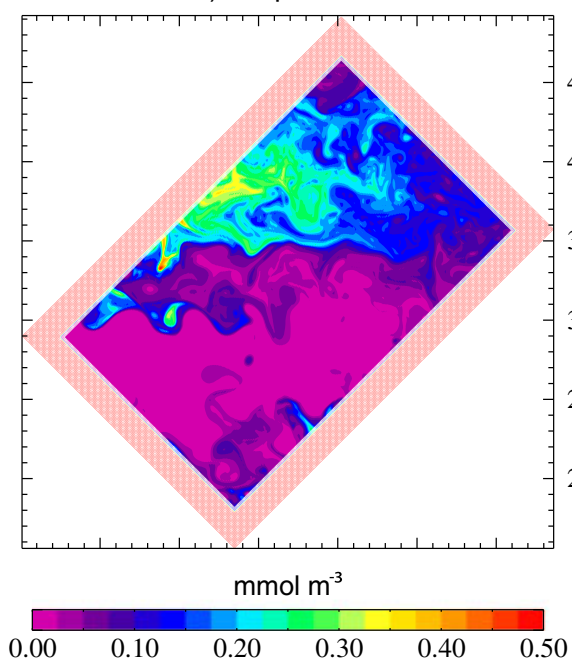

b) Phytoplankton

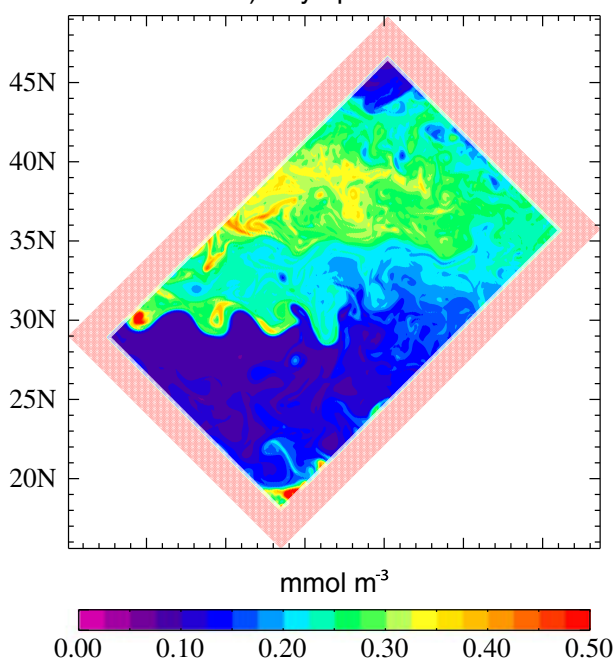

d) Annual mean Phytoplankton

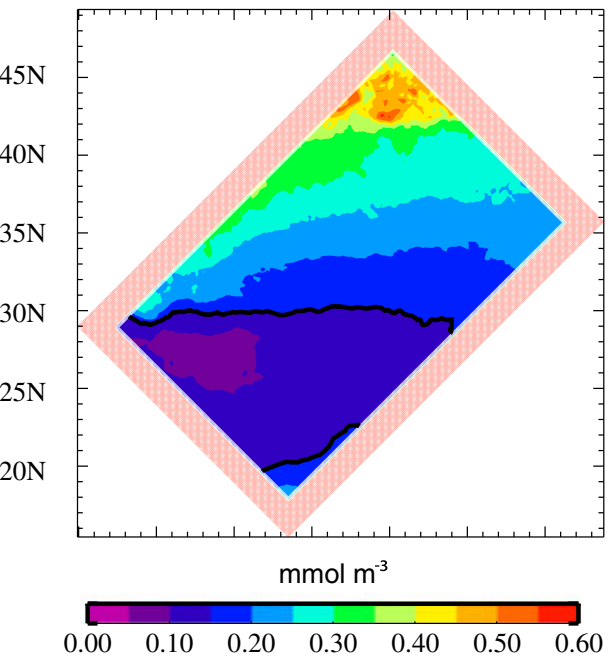

Figure 3. Model snapshots on 1 January at the surface of (a) nitrate, (b) phytoplankton, and (c) zooplankton. (d) The annual mean concentration of phytoplankton; the black contour $\left(0.15 \mathrm{mmol} \mathrm{N} / \mathrm{m}^{3}\right)$ is used to define the boundary between the subpolar and subtropical regions.

confirms that total and mean reactions differ by a small amount. The largest contribution of eddy reactions is found in the energetic jet area, where mesoscale fluctuations are the most pronounced, and reaches up to $\pm 40 \%$ there (Figure $5 \mathrm{f}$ ). Elsewhere, annual eddy reactions are generally of the order of $\pm 20 \%$ or less. Moreover, the contribution of eddy reactions is larger in the subtropical gyre than in the subpolar gyre, by approximately a factor of 2 .

\subsubsection{Sign of Eddy Reactions}

[29] At each latitude and throughout the year, eddy productivities are negative, and eddy grazing and eddy mortality are positive. In other words, the mean field approximation overestimates the total flux in the case of new and regenerated production and underestimates it for grazing and zooplankton mortality (Figures 4 and 5). Nonlinearities at the mesoscale and submesoscale thus tend to decrease phytoplankton production and to increase zooplankton grazing.

[30] Whether eddy reactions lead to an increase or decrease in the total reaction rate can be explained using their mathematical expression and the sign of the covariance between the variables in the expression. To illustrate this, let us consider a biogeochemical reaction $\mathcal{F}$, which depends on two state variables $A$ and $B$. The two-dimensional Taylor expansion of $\mathcal{F}$ permits us to approximate $\mathcal{F}$ as the sum of its mean field approximation plus second-order terms:

$$
\begin{aligned}
\mathcal{F}(A, B) \simeq & \mathcal{F}(\bar{A}, \bar{B})+0.5 \times \frac{\partial^{2} \mathcal{F}}{\partial A^{2}}(\delta A)^{2}+0.5 \times \frac{\partial^{2} \mathcal{F}}{\partial B^{2}}(\delta B)^{2} \\
& +\frac{\partial^{2} \mathcal{F}}{\partial A \partial B}(\delta A)(\delta B)
\end{aligned}
$$

[31] The small deviations $\delta A$ and $\delta B$ in our context represent the eddy fluctuations $A^{\prime}$ and $B^{\prime}$ defined previously, such that the eddy reactions for $\mathcal{F}(A, B)$ can be approximated by:

$$
\mathcal{F}^{\prime}(A, B) \simeq 0.5 \times \frac{\partial^{2} \mathcal{F}}{\partial A^{2}}\left(A^{\prime}\right)^{2}+0.5 \times \frac{\partial^{2} \mathcal{F}}{\partial B^{2}}\left(B^{\prime}\right)^{2}+\frac{\partial^{2} \mathcal{F}}{\partial A \partial B}\left(A^{\prime} B^{\prime}\right)
$$

[32] The simplest case to explore is that of zooplankton mortality, which is expressed as a quadratic function of $Z$ : 
a) Total and Mean reactions in subpolar gyre

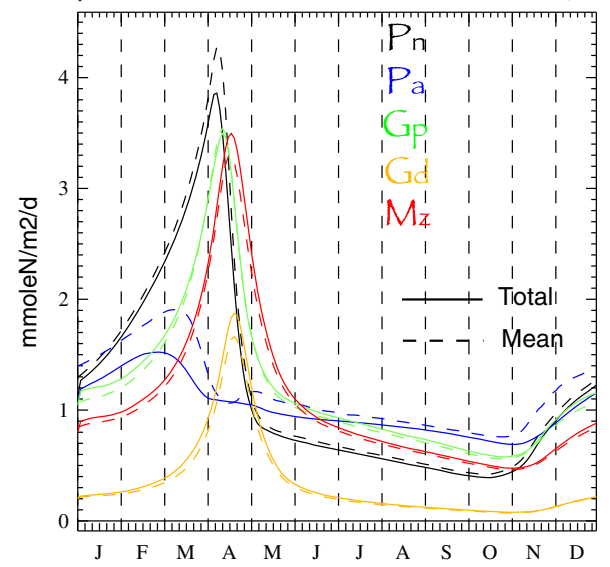

C) Eddy reactions in subpolar gyre

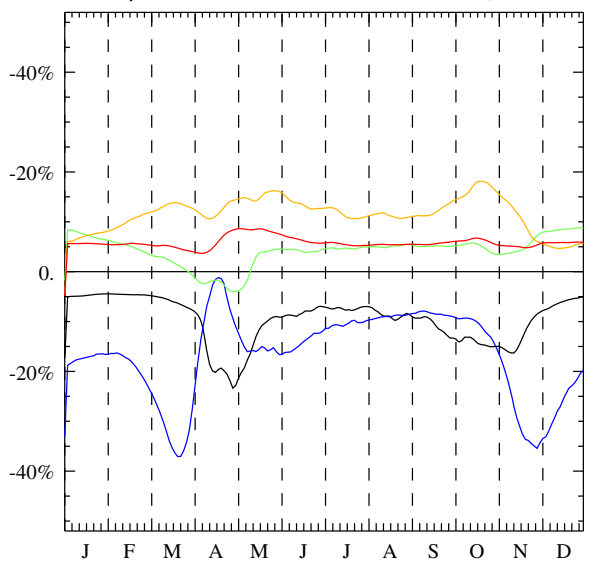

b) Total and Mean reactions in subtropical gyre

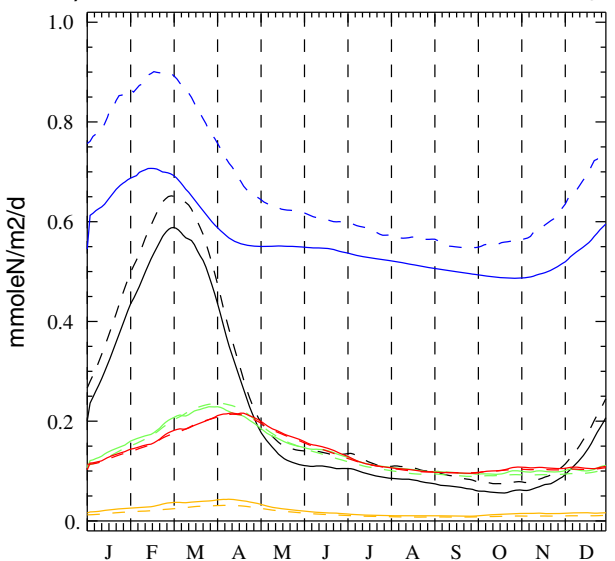

d) Eddy reactions in subtropical gyre

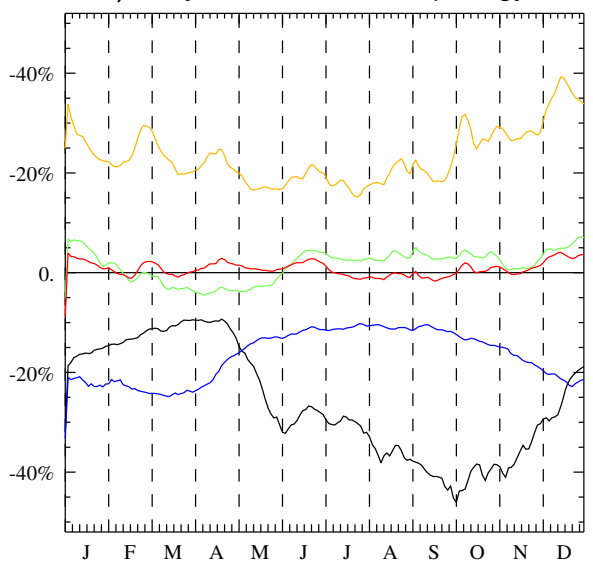

Figure 4. Seasonal evolution of new production $\mathcal{P}_{n}$, regenerated production $\mathcal{P}_{a}$, grazing of phytoplankton $\mathcal{G}_{p}$, grazing of detritus $\mathcal{G}_{d}$, and zooplankton mortality $\mathcal{M}_{z}$ in (a) the subpolar gyre and (b) the subtropical gyre. Total reactions (plain line) are computed by the submesoscale permitting model. Mean reactions (dashed line) are computed from the mean fields, i.e., neglecting variability at scales smaller than 2 days and $2^{\circ}$. (c and d) Corresponding eddy reactions are deduced from the difference between total and mean and shown as a percentage of the total. All terms are integrated over the top $120 \mathrm{~m}$.

$\mathcal{M}_{z}(Z)=m_{z} Z^{2}$. In this case, $\mathcal{M}_{z}^{\prime}(Z)=m_{z}\left(Z^{\prime}\right)^{2}$, and this expression is always positive, consistent with our numerical results (Figure 5e).

[33] The mathematical expressions for production and for grazing are more complex as they depend on more variables. The derivation of equation (5) is thus not as straightforward. However, both production and grazing follow MichaelisMenten kinetics, such that, at low values of the substrate (A), the flux to the consumer (B) is nearly bilinear in A and $\mathrm{B}\left(\mathcal{F}(A, B) \simeq \frac{\mu}{K} A B\right.$, with $\mu$ the growth or grazing rate and $\mathrm{K}$ the half saturation constant), while at large values of the substrate, $\mathcal{F}$ becomes nearly linear $(\mathcal{F}(A, B) \simeq \mu B)$. The associated eddy reaction is thus nonzero only at low substrate values, and due to the bilinear nature of the expression, exactly equals $\mathcal{F}^{\prime}=\frac{\mu}{K} A^{\prime} B^{\prime}$. Its sign is thus set by the sign of the covariance between the two variables involved. Moreover, this expression also tells us that the fractional contribution of the eddy reaction should be equal to $\mathrm{A}^{\prime} \mathrm{B}^{\prime} / \mathrm{AB}$ for low substrate concentrations. In the case of primary production, with $\mathrm{N}^{\prime}$ and $\mathrm{P}^{\prime}$ being of the order of $30 \%$ of $\mathrm{N}$ and $\mathrm{P}$ at most during the summer when $\mathrm{N}^{\prime}<\mathrm{K}^{\prime}$, this is consistent with the eddy productivity being less than $20 \%$ of primary production.

[34] In order to investigate further the signs of eddy productivity and eddy grazing, we examine the covariance between phytoplankton and nitrate and between phytoplankton and zooplankton. The enlarged areas of the model shown in Figures 6a-6c suggest that at small spatial scales, nitrate and phytoplankton are negatively correlated, while phytoplankton and zooplankton are positively correlated. This is confirmed in Figures 6d and 6e, which show a systematic positive covariance between phytoplankton and zooplankton small-scale variations at all depths in the euphotic layer, while the covariance between phytoplankton and nutrient is negative, except for a small depth range from 20 to $40 \mathrm{~m}$. The negative covariance between nitrate and phytoplankton at small scale can be explained by the contrasting vertical gradients of these two variables (phytoplankton being more abundant close to the surface and nutrient being more abundant at depth); so vertical velocities at the submesoscale 

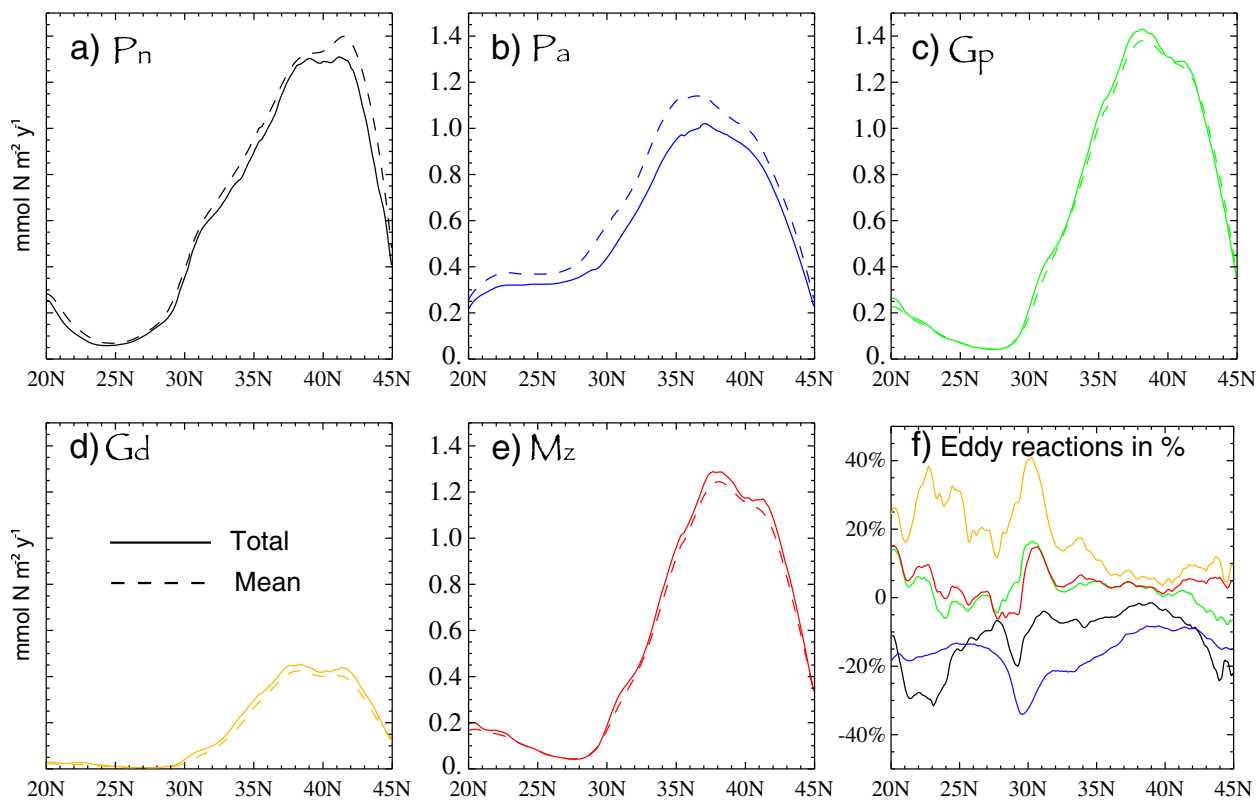

Figure 5. Total and mean biogeochemical reactions, integrated over the top $120 \mathrm{~m}$, over the zonal direction, and over 5 years. (a) New production, (b) regenerated production, (c) grazing of phytoplankton, (d) grazing of detritus, and (e) zooplankton mortality. Total reactions (plain line) are computed by the submesoscale permitting model. Mean reactions (dashed line) are computed from the mean fields, i.e., neglecting variability at scales smaller than 2 days and $2^{\circ}$. Eddy reactions are deduced from the difference between total and mean and shown as (f) a percentage of the total.

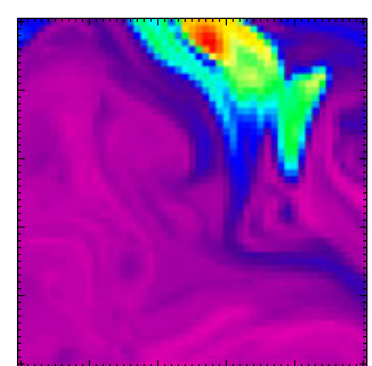

a) Nitrate $\left(\mathrm{mmolN} \mathrm{m}^{-3}\right)$

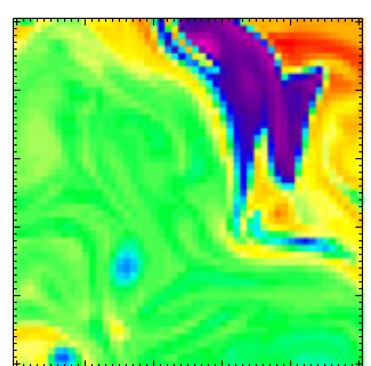

b) Phytoplankton ( $\mathrm{mmolN} \mathrm{m}^{-3}$ )

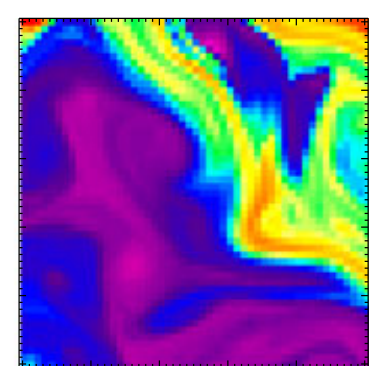

C) Zooplankton (mmolN m${ }^{-3}$ )

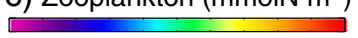

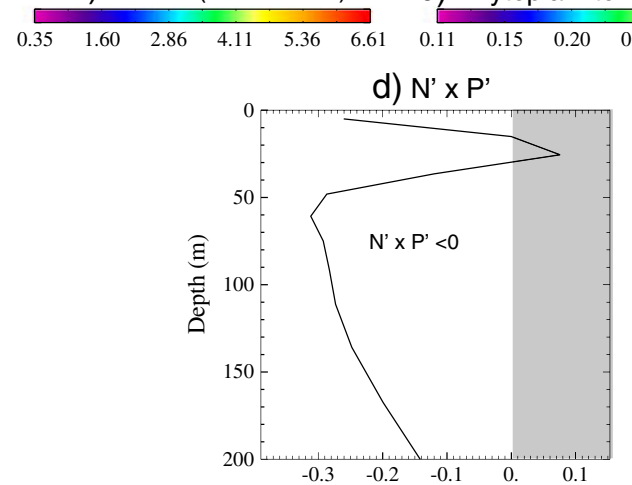

e) $P^{\prime} \times Z^{\prime}$

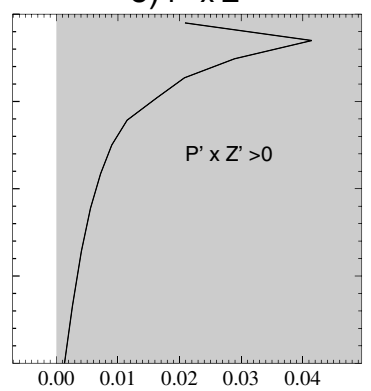

Figure 6. Enlarged box of $500 \mathrm{~km}$ x $500 \mathrm{~km}$ of the concentrations of (a) nitrate, (b) phytoplankton, and (c) zooplankton at $50 \mathrm{~m}$ depth. The distribution of $P$ and $N$ appears to be clearly anticorrelated, while those of $P$ and $Z$ tend to be more correlated. ( $g$ and $\mathrm{h}$ ) The vertical variation with depth of the cross product of $N^{\prime} P^{\prime}$ and $P^{\prime} Z^{\prime}$, respectively, averaged over the whole horizontal domain and over the 5 years of model data. Regions where this cross product is positive are shaded in grey. 


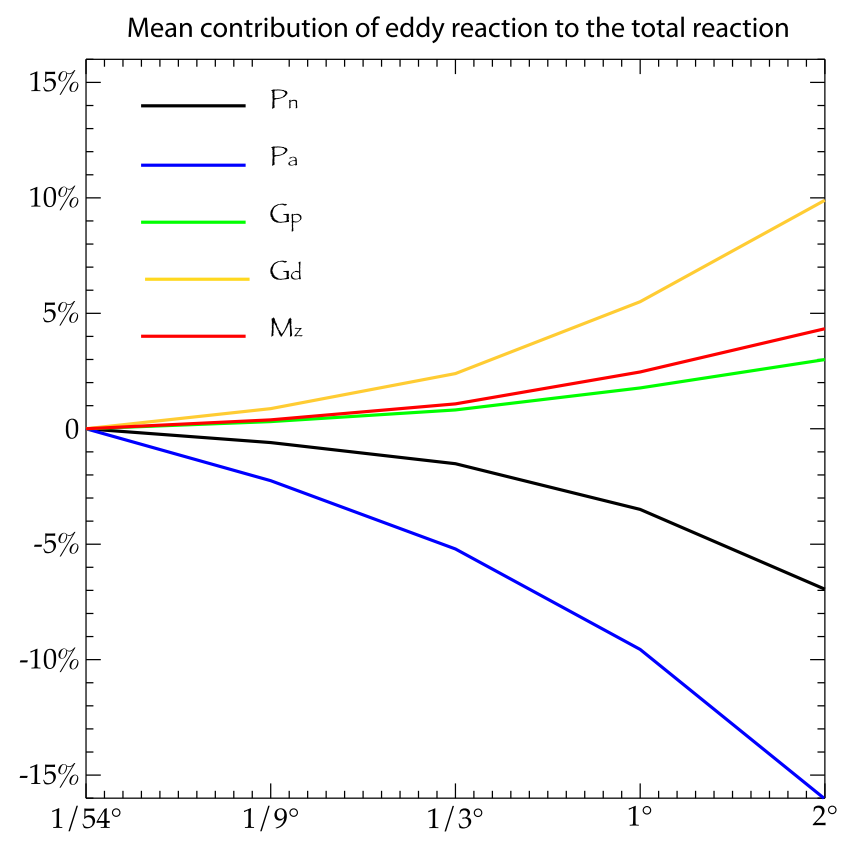

Figure 7. Strength of the domain-averaged, annual eddy reactions relatively to the domain-averaged, annual reaction and expressed in $\%$, for new production $\left(\mathcal{P}_{n}\right)$, regenerated production $\left(\mathcal{P}_{a}\right)$, grazing of phytoplankton $\left(\mathcal{G}_{p}\right)$, grazing of detritus $\left(\mathcal{G}_{d}\right)$, and zooplankton mortality $\left(\mathcal{M}_{z}\right)$. This contribution is computed using spatial filters of different sizes (represented on the $x$ axis). $1 / 54^{\circ}$ is the grid resolution, and thus, the eddy reaction at this scale is zero by construction. At $1 / 9^{\circ}, 1 / 3^{\circ}$, and $1^{\circ}$, we used box averaging over boxes of $1 / 9^{\circ}, 1 / 3^{\circ}$, and $1^{\circ}$, respectively. At $2^{\circ}$, we used a running filter of $2^{\circ}$ width combined with a 2 days climatological time filter (i.e., the same filter as that used in the rest of the paper).

typically transport a relative paucity of one tracer with an abundance of the other. Phytoplankton and zooplankton, however, have vertical gradients of the same sign, and their covariance due to submesoscale vertical circulations, although small, is positive. The vertical distributions of nutrient, phytoplankton, and zooplankton, combined with the heterogeneity at small scale which is generated by the vertical velocities, thus help explain why eddy productivities are systematically negative, while eddy grazing is positive.

\subsubsection{Scale Dependance}

[35] Phytoplankton, zooplankton, and nutrients exhibit variability at all scales from the large scale to the submesoscale, resulting from the tracer cascade toward small scales. The eddy-mean decomposition in equation (2) does not allow us to separate the contributions of mesoscale and submesoscale to eddy reactions. In order to quantify more precisely the strength of eddy reactions at different spatial scales, we have repeated the decomposition with a series of filters of different scales. More precisely, we used boxaveraged filters of $1^{\circ}, 1 / 3^{\circ}$, and $1 / 9^{\circ}$ width and compared the results with those obtained with the $2^{\circ}$ filter used throughout this study (Figure 7). On a domain average, the full eddy reaction, comprising the contribution of mesoscales down to submesoscales (i.e., from 10 to $100 \mathrm{~km}$ ), ranges between $-15 \%$ and $+10 \%$ of the total reaction; the largest eddy reactions are obtained for regenerated production and grazing of detritus. The contribution of submesoscales only (i.e., for filters between $1 / 3^{\circ}$ and $1 / 9^{\circ}$, i.e., between 10 and $30 \mathrm{~km}$ ) represents approximately $1 / 3$ of the eddy reaction (i.e., less that $5 \%$ of the total reaction), and this number is similar for all biogeochemical reactions considered here. This analysis suggests that eddy reactions are significantly stronger in the mesoscale range than in the submesoscale range.

\subsection{Comparison of Eddy Reactions and Eddy Fluxes}

[36] In this section, the strength of eddy reactions $\left(B_{N}^{\prime}, B_{P}^{\prime}\right.$, and $\left.B_{Z}^{\prime}\right)$ is compared to that of eddy transports $\left(A_{N}^{\prime}, A_{P}^{\prime}\right.$, and $\left.A_{Z}^{\prime}\right)$ in the annual mean balance of nitrate, phytoplankton, and zooplankton for the upper $120 \mathrm{~m}$ (equation (3)).

\subsubsection{Nitrate Balance}

[37] The different terms in the nitrate balance are plotted in Figure 8. Over the northern part of the domain, the main balance is between vertical mixing and the mean biogeochemical reaction (Figures $8 \mathrm{c}$ and $8 \mathrm{~d}$ ), more specifically between the amount of nitrate supplied to the euphotic layer by winter convective mixing and phytoplankton production which consumes it. Along the western boundary, nitrate is mainly provided through mean advection (Figures 8a and $8 \mathrm{~d}$ ), a route termed the "nutrient stream" in the North Atlantic [Williams et al., 2006]. Mean advection delivers nitrate into the interior of the domain through the zonal extension of the main jet (at $30^{\circ} \mathrm{N}$ ) and of secondary zonal jets (between $35^{\circ} \mathrm{N}$ and $40^{\circ} \mathrm{N}$ ). This mean advection is partly balanced by the eddy transports (Figure $8 \mathrm{~b}$ ), which remove nitrate from these two jet areas and redistribute it between $20^{\circ} \mathrm{N}$ and $30^{\circ} \mathrm{N}$ and between $30^{\circ} \mathrm{N}$ and $35^{\circ} \mathrm{N}$. The eddy reactions (i.e., equal in magnitude but opposite in sign to new production in the case of the nitrate equation) are negative almost everywhere but small compared to the mean reaction (Figures $8 \mathrm{~d}$ and $8 \mathrm{e}$ ).

[38] The quantities shown in Figure 8 are shown again in Figure9a after averaging along the zonal direction to allow easier comparison. The zonal quantities confirm the main balance between mean biology and vertical mixing, with a more significant contribution from total advection at middle latitudes $\left(30^{\circ} \mathrm{N}-40^{\circ} \mathrm{N}\right)$ and with a strong compensation between mean and eddy transports.

\subsubsection{Phytoplankton and Zooplankton Balances}

[39] Given the predominance of north-south variations in the two gyres system, the phytoplankton and zooplankton balances are shown after averaging along the zonal direction. The phytoplankton balance strongly differs from that of nitrate (Figure 9b). Unlike for nitrate, the transports for phytoplankton (total, mean, and eddy) are small compared to the other fluxes. The main balance is between vertical mixing and biogeochemical reactions: On an annual basis, losses of phytoplankton from the surface layer through vertical mixing are compensated by the biogeochemical sources and sinks. This net positive contribution arises as the net annual residual of seasonal variations showing larger positive and negative fluxes (Figure 4). Importantly, there is a strong compensation between mean and eddy reactions for phytoplankton.

[40] The total eddy reaction for phytoplankton is negative, and this can be explained using its expression $B_{P}^{\prime}=$ $(1-\gamma) \times\left(\mathcal{P}^{\prime}{ }_{n}+\mathcal{P}^{\prime}{ }_{a}\right)-\mathcal{G}^{\prime}{ }_{p}$, given that $\mathcal{P}^{\prime}{ }_{n}$ and $\mathcal{P}^{\prime}{ }_{a}$ are negative and $\mathcal{G}^{\prime}{ }_{p}$ is positive (see section 4.1.3). These three terms, 

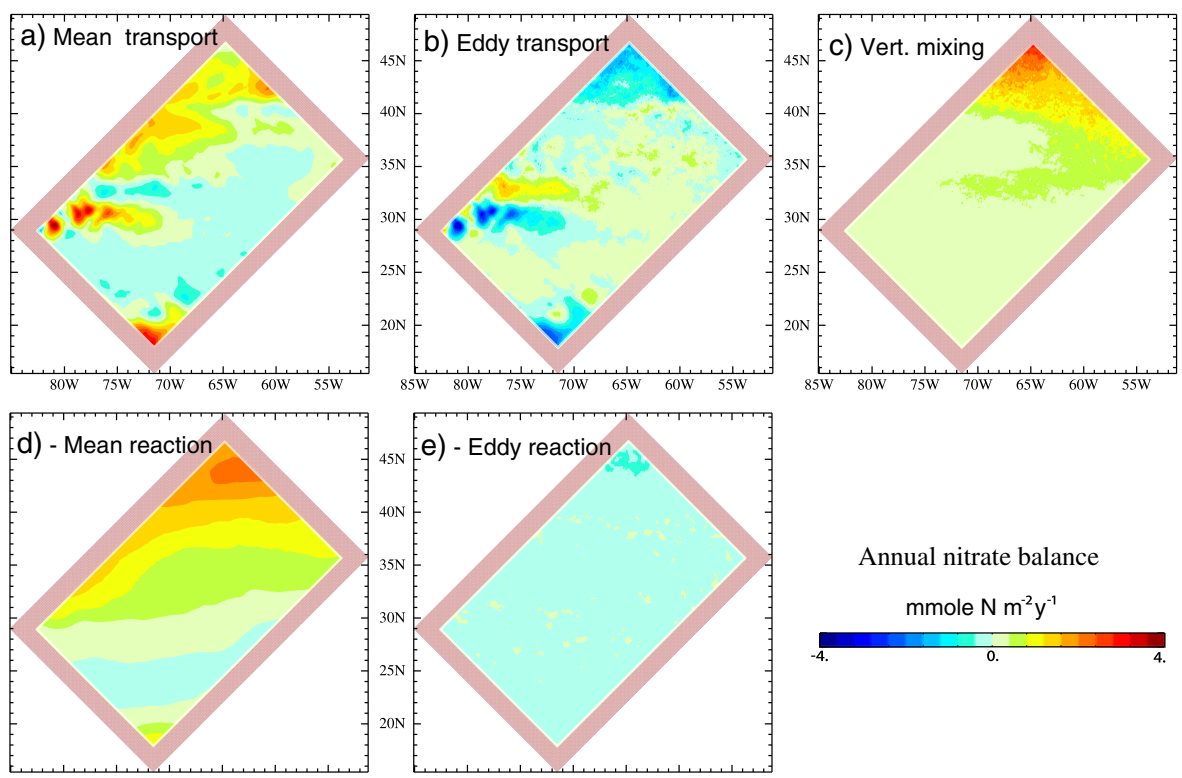

Annual nitrate balance

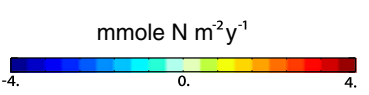

Figure 8. (a-e) Annual mean nitrate balance in the upper $120 \mathrm{~m}$ between mean transport, eddy transport, vertical mixing, mean reaction, and eddy reaction. To facilitate visual comparison, we plotted the inverse of the mean and eddy reaction, such that the sum of Figures $8 \mathrm{a}-8 \mathrm{c}$ in the first line is equal to the sum of Figures $8 \mathrm{~d}$ and $8 \mathrm{e}$ in the second line: $\left\langle A_{\bar{N}}\right\rangle+\left\langle A_{N}^{\prime}\right\rangle+\left\langle\overline{D_{N}}\right\rangle=-\left\langle B_{\bar{N}}\right\rangle-\left\langle B_{N}^{\prime}\right\rangle$.

a) NO3 balance
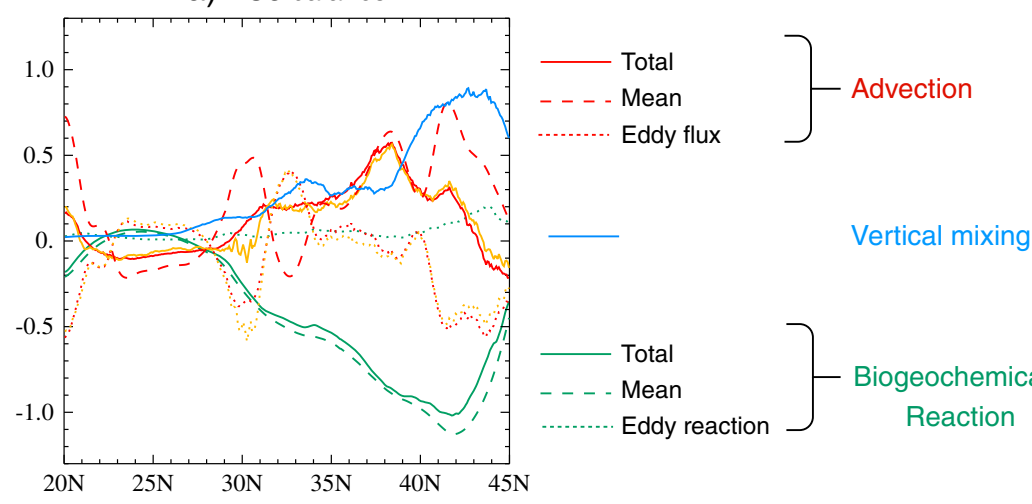

b) PHY balance
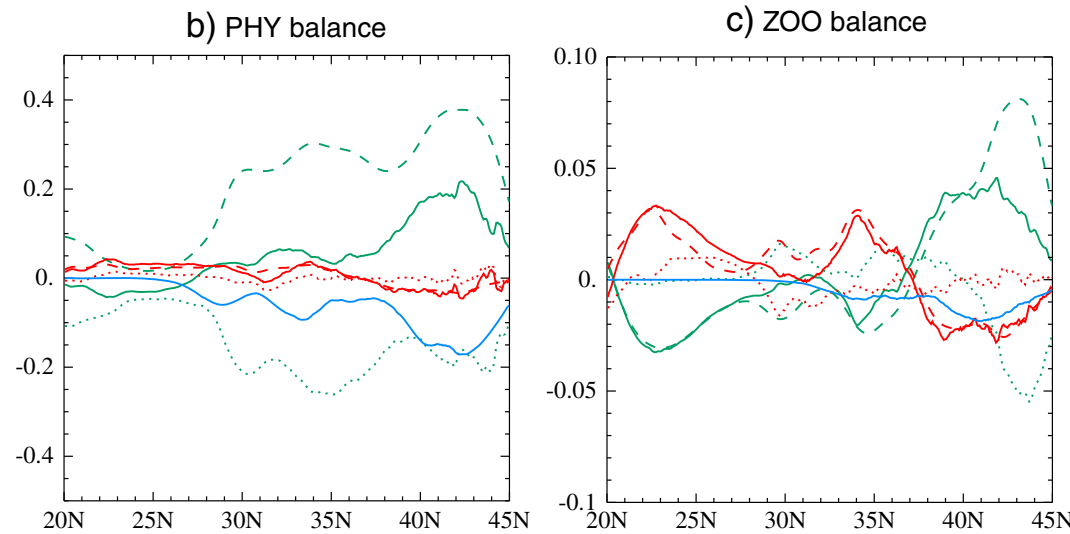

Figure 9. Nitrate, phytoplankton, and zooplankton annual balances between advective transport (total, eddy, mean), biogeochemical reactions (total, eddy, mean), and vertical mixing, averaged in the zonal direction. The balance implies that the sum of all terms is zero: $\left\langle A_{\bar{N}}\right\rangle+\left\langle A_{N}^{\prime}\right\rangle+\left\langle\overline{D_{N}}\right\rangle+\left\langle B_{\bar{N}}\right\rangle+\left\langle B_{N}^{\prime}\right\rangle=0$. 
although small when taken individually, are cumulatively more significant and thus make a significant contribution to the phytoplankton budget.

[41] In the case of zooplankton, the main balance is between mean reaction and mean transport up to $40^{\circ} \mathrm{N}$. North of this latitude, the contribution of eddy reaction becomes more important and partly compensates the large mean reaction.

[42] These results highlight the central role played by the eddy reactions in the phytoplankton (and, to a lesser extent, in the zooplankton) annual balance but not in the nitrate balance where they are negligible. Conversely, eddy transports are fundamental to the nitrate balance and much less so for phytoplankton and zooplankton. A possible explanation for the differing influence of transport and biogeochemical reactions on nitrate, phytoplankton, and zooplankton lies in their contrasting seasonal cycles. Nitrate is predominantly delivered to surface waters by convection over the winter. This is particularly true farther north, leading to the strong poleward increasing contribution from vertical mixing in Figure 9a. Over the winter months, when the nitrate concentrations are highest, there is little growth of phytoplankton and so a more dominant influence on nitrate concentration at a given location is through lateral dissipation by the mean and eddy transport fluxes. Come the spring, the rapid phytoplankton bloom consumes much of the available nitrate more rapidly than smaller scale gradients are generated and cascaded down to yet smaller scales. Consequently, the mean biological consumption largely balances the winter mixing source of nitrate, and the eddy reaction is small. For phytoplankton and zooplankton, however, the period when concentrations are at their most stable, during the winter, is also when they and their spatial gradients are lowest. Lacking the direct driving of winter convection (the effect of vertical mixing is confined to a smaller loss from the surface due to concentrations decreasing with depth), the tight coupling associated with the transmission of nitrogen through the ecosystem by the biological processes of growth and grazing means that they control the sources and sinks for plankton distributions more strongly than advection, with the dominant mean and eddy biogeochemical reactions largely balancing each other.

\section{Discussion}

[43] In the field of physical ocean modeling, considerable effort has been devoted to representing eddy transport in terms of the mean fields. The goal was, and remains, to resolve the smallest scales implicitly in terms of their effect on the larger scales, therefore allowing for coarser model grids and faster model runs [Gent and McWilliams, 1990; Gent et al., 1995; Pasquero, 2005; Fox-Kemper et al., 2008]. Less effort has been put into trying to represent implicitly the statistical effect of biogeochemical nonlinearities due to unresolved variability in plankton models, i.e., the eddy reactions discussed here. Although a few studies have started to address the issue of eddy reactions in marine biogeochemistry [e.g., Englund and Leonardsson, 2008; Wallhead et al., 2008, 2013; McKiver and Neufeld, 2009], they have so far focussed on deriving parameterizations for them using idealized situations as "testbeds," with none as yet applied to a simple basin scale model, let alone a global model.
Nevertheless, a number of "closures" show promise, particularly those making use of covariances between model fields. They already outperform mean field models in reproducing the behavior of a spatial model, often by some margin.

[44] In this study, however, we have taken an alternative perspective, instead addressing the question of whether it is even necessary to consider eddy reactions. The answer would seem, perhaps unsurprisingly, to depend on the question. If the primary interest is in biogeochemistry, and the dynamics and distribution of nutrients, then the results of this study suggest that the eddy reactions may be minor contributions compared to eddy transports. If, however, the interest is in the distribution of organisms, for example, to assess the strength of the biological carbon pump or the flux of organic material to higher trophic levels, then eddy reactions are of considerable importance. Moreover, we found that eddy reactions are strongly scale dependent which suggests that parameterizations for them should depend on resolution.

[45] The subtleties and robustness of this conclusion clearly merit further investigation. By definition, eddy reactions depend on the mathematical expression used to represent the biogeochemical reactions. There is in the literature a considerable range of expressions for primary production and grazing according to which data set, laboratory experiment and/or theoretical framework were used to derive them. The evaluation of the eddy reactions also depends on the wider biogeochemical model as this is responsible for generating the dynamics in populations and concentrations that contribute to the eddy reactions. This is not the place to discuss the much debated issue of model complexity [ $L e$ Quere et al., 2005; Anderson, 2006; Le Quere, 2006]. It should simply be noted that the results presented here were obtained using a single model and that future work should seek to test how robust they are across different models. However, the choice of parametrizations for biogeochemical reactions used here are typical of the rather simple models used in climate prediction. There is perhaps a greater need to test the conclusions with field data. However, although there are abundant data for phytoplankton, there are much less for other constituents of the ecosystem at the mesoscale. There remains considerable debate over the conversion of the various field measurements of zooplankton abundance to values that can be used in models and over how zooplankton and their interactions should be represented in those models [e.g., Gentleman et al., 2003]. It is also only relatively recently that optical methods have opened the way to high-resolution mapping of nitrate at the mesoscale and submesoscale [e.g. Pidcock et al., 2010; Johnson et al., 2010]. Nevertheless, we are now at a point where we can at least estimate eddy productivity. It may well be the case that such estimates in turn provide a new and rather demanding test of our models.

[46] It should also be noted that the study presented here has restricted itself to diagnosing mean and eddy reactions using full knowledge of the system at the time. It has not investigated the relative impact of those terms on the abundances of nutrients and organisms in the future. It is therefore also of interest to investigate how, for example, modeled seasonal cycles of phytoplankton abundance differ when they are calculated using full knowledge of the system and just the mean field. Some work has been done in simplified settings [e.g., Goodman, 2011; Wallhead et al., 2013], 


\section{LEVY AND MARTIN: INFLUENCE OF HETEROGENEITY}

but an investigation at a geochemically relevant scale is still lacking. In particular, it will be interesting to see to what extent the apparently small contributions by eddy reactions to key fluxes indicated by Figure 5 can nevertheless lead to a major divergence in behavior when integrated over an annual cycle. Figure 9 already offers an indication that the magnitude of individual eddy reactions might be misleading as it is the net flux through a component of the ecosystem that drives its evolution, and the magnitude of the eddy reaction contribution to this may strongly differs (Figure 5) from that of the individual components.

[47] Acknowledgments. The simulations were performed at IDRIS (France) from initial states computed on the supercomputer Earth Simulator (Earth Simulator Center, Yokohama, Japan). This project was supported by CNRS (INSU-LEFE TANGGO project), CNES (CPUMP project), and EUR-OCEANS submesoscale flagship. J. Le Sommer, X. Capet, P. Wallhead, and L. Resplandy provided insightful comments. The clarity of the paper was greatly improved, thanks to the comments from two anonymous reviewers and from the Editor, E. Sundquist. A.M. was supported in part by NERC National Capability funding.

\section{References}

Abraham, E. (1998), The generation of plankton patchiness by turbulent stirring, Nature, 391, 577-580.

Allen, J., L. Brown, R. Sanders, C. Moore, A. Mustard, S. Fielding, M. Lucas, M. Rixen, G. Savidge, and S. Henson (2005), Diatom carbon export enhanced by silicate upwelling in the northeast Atlantic, Nature, 437, 728-732.

Anderson, T. R. (2006), Confronting complexity: Reply to Le Quere and Flynn, J. Plankton Res., 28, 877-878.

Blanke, B., and P. Delecluse (1993), Variability of the tropical Atlantic Ocean simulated by a general circulation model with two different mixed-layer physics, J. Phys. Oceanogr., 23, 1363-1388.

Brentnall, S., K. Richards, and J. Brindley (2003), Plankton patchiness and its effect on larger-scale productivity, J. Plankton Res., 25, 121-140.

Capet, X., J. McWilliams, M. Molemaker, and A. Shchepetkin (2008), Mesoscale to submesoscale transition in the California Current System. Part I: Flow structure, eddy flux, and observational tests, J. Phys. Oceanogr., 38, 29-43.

Donaghay, P. L., and T. R. Osborn (1997), Toward a theory of biologicalphysical control of harmful algal bloom dynamics and impacts, Limnol. Ocennogr., 42, 1283-1296.

d'Ovidio, F., S. De Monte, S. Alvain, Y. Dandonneau, and M. Lévy (2010), Fluid dynamical niches of phytoplankton types, P. Natl. A. Sci., 107, $18,366-18,370$

Eden, C., R. J. Greatbatch, and D. Olbers (2007), Interpreting eddy fluxes, J. Phys. Oceanogr., 37, 1282-1296.

Edouard, S., B. Legras, F. Lefevre, and R. Eymard (1996), The effect of small-scale inhomogeneities on ozone depletion in the Arctic, Nature, $384,444-447$.

Englund, G., and K. Leonardsson (2008), Scaling up the functional response for spatially heterogeneous systems, Ecol. Lett., 11, 440-449.

Fox-Kemper, B., G. Danabasoglu, R. Ferrari, and R. W. Hallberg (2008), Parameterizing submesoscale physics in global models, Clivar Exch., 13, $3-5$.

Gent, P., J. Willebrand, T. McDougall, and J. McWilliams (1995), Parameterizing eddy-induced tracer transports in ocean circulation models, J. Phys. Oceanogr., 25, 463-474.

Gent, P. R., and J. C. McWilliams (1990), Isopycnal mixing in ocean circulation models, J. Phys. Oceanogr., 20, 150-155.

Gentleman, W., A. Leising, B. Frost, and S. Strom (2003), Functional responses for zooplankton feeding on multiple resources: A review of assumptions and biological dynamics, Deep Sea Research Part II, 50, $2847-2875$.

Goodman, L. (2011), Application of the Robinson biodynamical theory to turbulence, Dyn. Atmos. Oceans, 52, 8-19.

Goodman, L., and A. R. Robinson (2008), On the theory of advective effects on biological dynamics in the sea. III. The role of turbulence in biological-physical interactions, P. Roy. Soc. A-Math. Phy. Eng. Sci., $464,555-572$.

Johnson, K. S., S. C. Riser, and D. M. Karl (2010), Nitrate supply from deep to near-surface waters of the North Pacific subtropical gyre, Nature, $465,1062-1065$

Klein, P., B. Hua, G. Lapeyre, X. Capet, S. Le Gentil, and H. Sasaki (2008), Upper ocean turbulence from high-resolution 3D simulations, J. Phys. Oceanogr., 38, 1748-1763.
Le Quere, C. (2006), Reply to Horizons Article "Plankton functional type modelling: Running before we can walk" Anderson (2005): I. Abrupt changes in marine ecosystems?, J. Plankton Res., 28, 871-872.

Lehahn, Y., F. d'Ovidio, M. Levy, and E. Heifetz (2007), Stirring of the northeast Atlantic spring bloom: A Lagrangian analysis based on multisatellite data, J. Geophys. Res., 112, C08005, doi:10.1029/ 2006JC003927.

Le Quere, C., S. P. Harrison, and I. C. Prentice (2005), Ecosystem dynamics based on plankton functional types for global ocean biogeochemistry models, Global Change Biol., 11, 2016-2040.

Lévy, M., A. Estublier, and G. Madec (2001), Choice of an advection scheme for biogeochemical models, Geophys. Res. Lett., 28, 3725-3728.

Lévy, M., R. Ferrari, P. J. S. Franks, A. P. Martin, and P. Rivière (2012a), Bringing physics to life at the submesoscale, Geophys. Res. Lett., 39, L14602, doi:10.1029/2012GL052756.

Lévy, M., M. Gavart, L. Mémery, G. Caniaux, and A. Paci (2005), A fourdimensional mesoscale map of the spring bloom in the northeast Atlantic (POMME experiment): Results of a prognostic model, J. Geophys. Res., 110, C07S21, doi:10.1029/2004JC002588.

Lévy, M., D. Iovino, L. Resplandy, P. Klein, G. Madec, A. M. Tréguier, S. Masson, and K. Takahashi (2012b), Large-scale impacts of submesoscale dynamics on phytoplankton: Local and remote effects, Ocean Modell., 43-44, 77-93.

Lévy, M., and P. Klein (2004), Does the low frequency variability of mesoscale dynamics explain a part of the phytoplankton and zooplankton spectral variability? P. Roy. Soc. A-Math. Phy. Eng. Sci., 460, 1673-1687.

Lévy, M., P. Klein, A. M. Tréguier, D. Iovino, G. Madec, S. Masson, and K. Takahashi (2010), Modifications of gyre circulation by sub-mesoscale physics, Ocean Modell., 34, 1-15.

Madec, G. (2008), NEMO ocean engine, Note du Pole de modelisation de l'Institut Pierre-Simon Laplace, 27, 1-217.

Martin, A. (2003), Phytoplankton patchiness: The role of lateral stirring and mixing, Prog. Oceanogr., 57, 125-174.

Martin, A., K. Richards, A. Bracco, and A. Provenzale (2002), Patchy productivity in the open ocean, Global Biogeochem. Cycles, 16(2), 1025 , doi:10.1029/2001GB001449.

Martin, A. P., and M. Srokosz (2002), Plankton distribution spectra: Inter-size class variability and the relative slopes for phytoplankton and zooplankton, Geophysical Research Letters, 29(24), 2213, doi:10.1029/2002GL015117.

McGillicuddy, D., L. Anderson, S. Doney, and M. Maltrud (2003), Eddydriven sources and sinks of nutrients in the upper ocean: Results from a 0.1 resolution model of the North Atlantic, Global Biogeochem. Cycles, 2, 1035, doi:10.1029/2002GB001987.

McKiver, W., and Z. Neufeld (2009), Influence of turbulent advection on a phytoplankton ecosystem with nonuniform carrying capacity, Phys. Rev. $E, 79,061902$.

Michaelis, L., and M. Menten (1913), Die kinetik der invertinwirkung, Biochemistry, 49, 333-369.

Oschlies, A. (2002), Can eddies make ocean deserts bloom? Global Biogeochem. Cycles, 16(4), 1106, doi:10.1029/2001GB001830.

Pasquero, C. (2005), Differential eddy diffusion of biogeochemical tracers, Geophys. Res. Lett., 32, L17603, doi:10.1029/2005GL023662.

Pasquero, C., A. Bracco, and A. Provenzale (2005), Impact of the spatiotemporal variability of the nutrient flux on primary productivity in the ocean, J. Geophys. Res., 110, C07005, doi:10.1029/2005GL023662.

Pidcock, R., M. Srokosz, J. Allen, M. Hartman, S. Painter, M. Mowlem, D. Hydes, and A. Martin (2010), A novel integration of an ultraviolet nitrate sensor on board a towed vehicle for mapping open-ocean submesoscale nitrate variability, J. Atmos. Oceanic Technol., 27, 1410-1416.

Richards, K., and S. Brentnall (2006), The impact of diffusion and stirring on the dynamics of interacting populations, J. Theor. Biol., 238, 340-347.

Srokosz, M., A. Martin, and M. Fasham (2003), On the role of biological dynamics in plankton patchiness at the mesoscale: An example from the eastern North Atlantic Ocean, J. Mar. Res., 61, 517-537.

Thomas, L., A. Tandon, and A. Mahadevan (2008), Submesoscale processes and dynamics. Eddy resolving ocean models, Geophys. Monogr., 177, $17-38$.

Tsuda, A., H. Sugisaki, T. Ishimaru, and T. Saino (1993), White-noise-like distribution of the oceanic copepod Neocalanus cristatus in the subarctic North Pacific, Mar. Ecol. Prog. Ser., 97, 39-46.

Wallhead, P. J., V. C. Garçon, and A. P. Martin (2013), Efficient upscaling of ocean biogeochemistry, Ocean Modell., 63, 40-55.

Wallhead, P. J., A. P. Martin, and M. A. Srokosz (2008), Spatially implicit plankton population models: Transient spatial variability, J. Theor. Biol., 253, 405-423.

Williams, R., V. Roussenov, and M. Follows (2006), Nutrient streams and their induction into the mixed layer, Global Biogeochem. Cycles, 20, GB1016, doi:10.1029/2005GB002586. 